\title{
Pengembangan Bahan Ajar Tematik Berbasis Keunggulan Lokal Kabupaten Kebumen untuk Meningkatkan Hasil Belajar pada Tema 6 Subtema 2 di Kelas IV SD N Tahun Ajaran 2018/2019
}

\author{
Teguh Rahayu ${ }^{1}$, Kartika Chrysti Suryandari ${ }^{2}$, Ngatman $^{3}$ \\ 1,2,3 Universitas Sebelas Maret \\ rahayuteguh99@gmail.com
}

\section{Article History}

accepted 01/10/2019

\begin{abstract}
Development of Local Excellence-Based Thematic Teaching Materials in Kebumen Regency to Improve Learning Outcomes in Theme 6 of Subtema 2 in Class IV SD N 4 Pejagoan Academic Year 2018/2019. This study aims to analyze the feasibility of teaching materials and test the effectiveness of teaching materials to improve learning outcomes in theme 6 of sub-theme 2 in class IV SD N 4 Pejagoan 2018/2019 academic year. The type of research used is research and development or Research and Development $(R n D)$. The development model used is the model of Borg \& Gall (1989). This research was carried out in the fourth grade of SD Negeri 4 Pejagoan with the teacher as the subject of field testing and students as the target of field test subjects. The types of data used are quantitative and qualitative data. The instruments of data collection used were interviews, observations, questionnaires and the results of the pre-test and post-test. The data analysis technique used is descriptive analysis, analysis prerequisite test (normality test and homogeneity test), and effectiveness test of teaching materials (t-test and effect size). The results of this study indicate that thematic teaching materials based on local superiority of Kebumen Regency are feasible to be used in learning and can improve student learning outcomes in theme 6 of sub-theme 2 in grade IV elementary school.
\end{abstract}

Keywords: teaching materials, thematic learning, local excellence

\begin{abstract}
Abstrak
Penelitian ini bertujuan untuk menganalisis kelayakan bahan ajar dan menguji keefektifan bahan ajar untuk meningkatkan hasil belajar pada tema 6 subtema 2 di kelas IV SD N 4 Pejagoan tahun ajaran 2018/2019. Jenis penelitian yang digunakan adalah penelitian dan pengembangan atau Research and Development $(R n D)$. Model pengembangan yang digunakan adalah model Borg \& Gall (1989). Penelitian ini dilaksanakan di kelas IV SD Negeri 4 Pejagoan dengan guru sebagai subjek uji lapangan dan siswa sebagai sasaran subjek uji lapangan. Jenis data yang digunakan adalah data kuantitatif dan kualitatif. Instrumen pengumpulan data yang digunakan berupa wawancara, observasi, angket serta hasil pre-test dan post test. Teknik analisis data yang digunakan, yaitu analisis deskriptif, uji prasyarat analisis (uji normalitas dan uji homogenitas), dan uji kefektifan bahan ajar (uji-t dan effect size). Hasil penelitian ini menunjukkan bahwa bahan ajar tematik berbasis keunggulan lokal Kabupaten Kebumen layak digunakan dalam pembelajaran dan dapat meningkatkan hasil belajar siswa pada tema 6 subtema 2 di kelas IV SD.
\end{abstract}

Kata kunci: bahan ajar, pembelajaran tematik, keunggulan lokal 


\section{PENDAHULUAN}

Saat ini dunia pendidikan telah memasuki abad 21. Pada abad 21, siswa dituntut untuk dapat menyesuaikan diri dengan cara menguasai empat keterampilan. Keterampilan tersebut dikenal dengan istilah $4 C$, yaitu communication, collaboration, critical thinking and problem solving, serta creativity and inovation. Keterampilan $4 C$ merupakan keterampilan yang ingin dicapai pada kurikulum 2013 melalui pembelajaran tematik. Akbar, dkk. (2016:17) mengemukakan bahwa pembelajaran tematik merupakan model dari kurikulum terpadu yang menggunakan tema untuk mengaitkan beberapa mata pelajaran sehingga dapat memberikan pengalaman bermakna untuk siswa. Pengalaman belajar yang bermakna dapat diperoleh dengan memanfaatkan buku siswa sebagai bahan ajar. Depdiknas (2008:6) menyatakan bahwa bahan ajar yang digunakan dalam pembelajaran perlu dikembangkan agar relevan dan sejalan dengan kehidupan di lingkungan sekitar siswa. Salah satu cara yang dapat digunakan yaitu dengan memasukkan unsur keunggulan lokal ke dalam bahan ajar. Berdasarkan hal tersebut, alangkah baiknya guru dapat mengembangkan bahan ajar berbasis keunggulan lokal, sebagai lingkungan terdekat siswa.

Berdasarkan hasil observasi dan wawancara dengan guru kelas IV SD N 4 Pejagoan pada hari Selasa, 02 Oktober 2018 diperoleh informasi bahwa kurikulum 2013 di SD N 4 Pejagoan dilaksanakan mulai tahun ajaran 2018/2019. Dalam pelaksanaannya memiliki beberapa permasalahan, yaitu (1) buku yang digunakan hanya buku dari pemerintah dan buku dari penerbit; (2) belum tersedianya bahan ajar tematik berbasis keunggulan lokal Kabupaten Kebumen; (3) materi pembelajaran bersifat umum, kurang konkret, dan kurang dekat dengan lingkungan siswa; (4) kurangnya pengenalan keunggulan lokal Kabupaten Kebumen dalam pembelajaran; (5) hasil belajar siswa kurang maksimal, hal ini dilihat dari rata-rata nilai UTS sebesar 68,1 .

Berdasarkan uraian di atas, peneliti termotivasi untuk melakukan penelitian pengembangan bahan ajar yang kedepannya akan menghasilkan bahan ajar dengan mengangkat konteks keunggulan lokal. Dengan demikian, judul dari penelitian ini adalah "Pengembangan Bahan Ajar Tematik Berbasis Keunggulan Lokal Kabupaten Kebumen untuk Meningkatkan Hasil Belajar pada Tema 6 Subtema 2 di Kelas IV SD Tahun Ajaran 2018/2019". Dalam hal ini, bahan ajar yang dikembangkan berupa buku teks pelajaran dalam bentuk cetak.

Dengan demikian, penelitian dan pengembangan ini memiliki tujuan sebagai berikut: 1) menganalisis kelayakan bahan ajar tematik berbasis keunggulan lokal Kabupaten Kebumen untuk meningkatkan hasil belajar pada tema 6 subtema 2 di kelas IV SD tahun ajaran 2018/2019; 2) menguji keefektifan bahan ajar tematik berbasis keunggulan lokal Kabupaten Kebumen untuk meningkatkan hasil belajar pada tema 6 subtema 2 di kelas IV SD tahun ajaran 2018/2019.

\section{METODE}

Jenis penelitian yang digunakan adalah penelitian dan pengembangan atau Research and Development $(R n D)$. Model pengembangan yang digunakan adalah model Borg \& Gall (1989).

Penelitian ini dilaksanakan di kelas IV SD Negeri 4 Pejagoan yang beralamat di jalan Pejagoan, Legok Kidul, Pejagoan, Kebumen, dengan guru sebagai subjek uji lapangan dan siswa dengan jumlah 21 yang terdiri dari 10 siswa laki-laki dan 11 siswa perempuan sebagai sasaran subjek uji lapangan.

Jenis data yang digunakan adalah data kuantitatif dan kualitatif. Data kuantifatif diperoleh dari angket penilaian oleh ahli materi, ahli media, guru, dan siswa serta nilai pre-test dan post-test. Data kualitatif diperoleh dari: 1) kritik, saran, dan komentar dari validator; 2) kesimpulan berupa pernyataan kelayakan bahan ajar; 3) komentar dari guru dan siswa. Instrumen pengumpulan data yang digunakan berupa angket, 
wawancara, observasi, serta hasil ketercapaian hasil belajar (pre-test dan post test). Teknik analisis data yang digunakan dalam penelitian ini, yaitu analisis deskriptif, uji prasyarat analisis (uji normalitas dan uji homogenitas), dan uji kefektifan bahan ajar (uji-t dan effect size).

Untuk mengetahui kelayakan bahan ajar, data yang diperoleh berupa data kuantitatif yang dikonversikan ke data kualitatif. Berikut konversi data kuantitatif ke kualitatif, yang diadaptasi dari Azwar (Sya'ban dan Wilujeng, 2011:163).

Tabel 1. Konversi Data Kuantitatif ke Kualitatif

\begin{tabular}{|c|c|c|}
\hline Interval Nilai & Rerata Skor & Kriteria \\
\hline $\mathrm{Mi}+1,5 \mathrm{Sbi}<\mathrm{X}$ & $4<X$ & Sangat baik \\
\hline $\mathrm{Mi}+0,5 \mathrm{Sbi}<\mathrm{X} \leq \mathrm{Mi}+1,5 \mathrm{Sbi}$ & $3,34<\mathrm{X} \leq 4$ & Baik \\
\hline $\mathrm{Mi}-0,5 \mathrm{Sbi}<\mathrm{X} \leq \mathrm{Mi}+0,5 \mathrm{Sbi}$ & $2,66<X \leq 3,34$ & Cukup baik \\
\hline $\mathrm{Mi}-1,5 \mathrm{Sbi}<\mathrm{X} \leq \mathrm{Mi}-0,5 \mathrm{Sbi}$ & $2<X \leq 2,66$ & Kurang baik \\
\hline $\mathrm{X} \leq \mathrm{Mi}-1,5 \mathrm{Sbi}$ & $X \leq 2$ & Sangat kurang baik \\
\hline
\end{tabular}

Untuk mengetahui keefektifan bahan ajar untuk meningkatkan hasil belajar siswa melalui effect size menggunakan kriteria Cohen (Sullivan dan Feinn, 2012:280), yaitu sebagai berikut.

Tabel 2. Interpretasi Effect Size

\begin{tabular}{ll}
\hline Effect Size & Interpretasi \\
\hline $0,2 \leq \mathrm{d}<0,4$ & Small \\
$0,5 \leq \mathrm{d} \leq 0,8$ & Medium \\
$0,8 \leq \mathrm{d} \leq 1,2$ & Large \\
$\mathrm{d} \geq 1,3$ & Very Large \\
\hline
\end{tabular}

HASIL DAN PEMBAHASAN

Kelayakan bahan ajar dinilai oleh ahli (ahli materi dan ahli media) dan keterbacaan bahan ajar dinilai oleh guru dan siswa. Hasil penilaian kelayakan bahan ajar menunjukkan bahwa bahan ajar yang dikembangkan layak digunakan dalam pembelajaran, sesuai untuk digunakan dalam pembelajaran, dan memudahkan siswa dalam memahami materi. Sejalan dengan hasil penilaian melalui angket, yaitu sebagai berikut.

Tabel 3. Kelayakan Bahan Ajar

\begin{tabular}{llll}
\hline No & Penilai & Nilai & Kriteria \\
\hline 1. & Ahli Materi & 3,56 & Baik \\
2. & Ahli Media & 3,73 & Baik \\
\hline
\end{tabular}

Berdasarkan tabel 3, dapat diketahui bahwa kelayakan bahan ajar dari ahli materi sebesar 3,56 dengan kriteria baik dan ahli media 3,68 dengan kriteria baik.

Tabel 4. Keterbacaan Bahan Ajar

\begin{tabular}{llll}
\hline No & Penilai & Nilai & Kriteria \\
\hline 1. & Guru & 4,11 & Sangat baik \\
2. & Siswa & 4,21 & Sangat baik \\
\hline
\end{tabular}

Berdasarkan tabel 4, dapat diketahui bahwa keterbacaan bahan ajar dari guru sebesar 4,11 dengan kriteria sangat baik dan dari siswa sebesar 4,21 dengan kriteria sangat baik. 
Keefektifan bahan ajar untuk meningkatkan hasil belajar dapat dilihat melalui nilai uji-t dan effect size, yaitu sebagai berikut.

\begin{tabular}{lc}
\multicolumn{2}{c}{ Tabel 5 Keefektifan Bahan Ajar } \\
\hline Keefektifan Bahan Ajar & Hasil \\
\hline Uji-t & 8,4288 \\
Effect size & 2,11 \\
\hline
\end{tabular}

Berdasarkan tabel 5, diperoleh nilai thitung sebesar 8,4288 dan nilai tabel 2,086. Jadi, dapat disimpulkan bahwa terdapat perbedaan yang signifikan antara sebelum dan sesudah menggunakan bahan ajar tematik berbasis keunggulan lokal Kabupaten Kebumen. Nilai effect size sebesar 2,11 dengan interpretasi very large, maka dapat disimpulkan bahwa bahan ajar memberikan kontribusi yang sangat besar dalam meningkatkan hasil belajar siswa.

Bahan ajar yang dikembangkan layak dan sesuai untuk digunakan dalam pembelajaran serta memudahkan siswa dalam memahami materi. Hal ini sejalan dengan pendapat Suratmi, Laihat, dan Santri (2018:36); Yenni, Hermani, dan Widodo (2016:1) yang menyatakan bahwa salah satu cara untuk meningkatkan kualitas pembelajaran adalah dengan menggunakan bahan ajar yang tepat, sehingga memberikan kemudahan bagi siswa dalam mengembangkan pengetahuan dan mencapai tujuan pembelajaran.

Dengan demikian, melalui bahan ajar yang dikaitkan dengan keunggulan lokal Kabupaten Kebumen sebagai lingkungan terdekat dengan siswa dapat meningkatkan hasil belajar siswa karena memudahkan siswa untuk belajar secara langsung. Sesuai dengan pendapat yang dikemukakan oleh Anderson dan Krathwohl (Laksana, Kurnia, dan Nitalia, 2016:2) yang menyatakan bahwa siswa di setiap di Indonesia berbeda satu sama lain, maka perlu dilakukan identifikasi unsur budaya lokal (keunggulan lokal) dalam sumber belajar untuk menjadikan kelas aktif guna mencapai pengalaman belajar bermakna. Selain itu Ardan (2016:191); Subijanto (2015:118); Suratmi, Laihat, dan Santri (2016:37) perlu adanya pengembangan bahan ajar berbasis keunggulan lokal sebagai bahan ajar kontekstual yang menarik, sehingga siswa akan memahami dan tidak akan pernah melupakan nilai-nilai budaya lokalnya sendiri. Dengan belajar dari lingkungan terdekatnya, yaitu belajar dari daerahnya, siswa akan lebih mudah memahami materi pembelajaran dan juga dapat melestarikan budaya lokalnya.

\section{SIMPULAN}

Kelayakan bahan ajar menunjukkan bahwa bahan ajar yang dikembangkan layak digunakan dalam pembelajaranm dan efektif untuk meningkatkan hasil belajar siswa kelas IV SD N 4 Pejagoan. Selain itu, siswa menjadi lebih mengenal budaya lokalnya.

Bahan ajar tematik berbasis keunggulan lokal Kabupaten Kebumen pada tema 6 Cita-Citaku subtema 2 Hebatnya Cita-Citaku untuk siswa kelas IV SD dapat dimanfaatkan sebagai: 1) buku pendukung atau penunjang dalam menyampaikan materi pembelajaran pada tema 6 subtema 2 kelas IV SD; 2) dapat diperbanyak dan digunakan secara lebih luas; 3 ) perlu dikembangkan lebih luas untuk tema dan subtema lain dalam pembelajaran tematik; 4) diperluas untuk kelas lain dalam pembelajaran tematik.

\section{DAFTAR PUSTAKA}

Akbar, S., dkk (2016). Implementasi Pembelajaran Tematik di Sekolah Dasar. Bandung: PT Remaja Rosdakarya. 
Ardan, A. S. (2016). The Development of Biology Teaching Material Based on the Local Wisdom of Timorese to Improve Student Knowledge and Attitude of Environment In Caring the Preservation of Environment. International Journal Of Higher Education. 5(3): 191. Diperoleh pada tanggal 17 November 2016 dari http://www.sciedu.ca/ journal/index.php/ijhe/article/ view/10052.

Depdiknas. (2008). Panduan Pengembangan Bahan Ajar. Jakarta: Departemen Pendidikan Nasional Direktorat Jenderal Manajemen Pendidikan Dasar dan Menengah, Direktorat Pembinaan Sekolah Menengah Atas.

Laksana, D.N.L., Kurniawan, P. A. W., dan Nitalia, I. (2016). Pengembangan Bahan Ajar Tematik Berbasis Kearifan Lokal Masyarakat Ngada (Versi Elektronik). Jurnal Ilmiah Pendidikan Citra Bakti. 3(1): 2. Diperoleh pada tanggal 10 November 2018, http://ejournal.citrabakti.ac.id/index.php/iipcb/article/view/74.

Prastowo, A. (2012). Panduan Kreatif Membuat Bahan Ajar Inovatif. Jogjakarta: DIVA Press.

Sullivan, G. M dan Feinn, R. (2012). Using Effect Size or Why The P Value is Not Enough. Journal of Graduate Medical Education. 4(3): 280. Diperoleh pada tanggal 10 Desember 2018 dari http://www.jgme.org/doi/abs/10.4300/ JGME-D12-00156.1.

Subijanto. (2015). Kebijakan Program Pendidikan Berbasis Keunggulan Lokal di Sekolah Menengah Atas Negeri 2 Pekalongan. Jurnal Pendidikan dan Kebudayaan. 21(2): 118. Diperoleh pada tanggal 10 November 2018 dari https://media.neliti.com/.../124451IDkebijakanprogrampendidikanberbasis-ke.pdf.

Suratmi, Laihat, dan Santri, D. J. (2018). Development of Teaching Material Based on Local Excellences of South Sumatera for Science Learning in Elementary School. Jurnal Penelitian dan Pembelajaran IPA. 4(1): 36. Diperoleh pada tanggal 14 November 2018 dari http://jurnal.untirta.ac.id/ index.php/JPPI/article/view/36.

Sya'ban, M. F dan Wilujeng, I. (2016). Pengembangan SSP Zat dan Energi Berbasis Keunggulan Lokal untuk Meningkatkan Literasi Sains dan Kepedulian Lingkungan. Jurnal Inovasi Pendidikan IPA. 2(1): 29. Diperoleh pada 11 November 2018 dari https://journal.uny.ac.id/index.php/iipi/article/view/ 8369.

Yenni, R., Hermani, Widodo, A. (2016). The Implementation of Integrated Science Teaching Materials Based Sosio-scientific Issues to Improve Students Scientific Literacy for Enviromental Pollution Theme. Mathematics, Science, and Computer Science Education. 1848(1): 1. Diperoleh pada tanggal 14 November 2018 darihttps://doi.org/10.1063/1.983970. 